\title{
A Globalização e a Revolta Populista em Democracias
}

\section{Liberais Ocidentais*}

\author{
Giovanna Macieira Rosário ${ }^{1}$
}

\section{Resumo}

Este artigo possui como objetivo a compreensão da ascensão de movimentos populistas em democracias liberais ocidentais. Tendo isso em vista, pretende-se examinar a relação entre esse fenômeno e a globalização. Dessa forma, após a compreensão das características essenciais do populismo, busca-se a análise da forma como a globalização influi sobre o nível do doméstico. Sendo assim, são analisadas duas dimensões distintas da globalização - a econômica e a cultural - com o propósito de apreender os efeitos do papel da insegurança econômica e existencial sobre a ascensão desses movimentos que buscam a contestação da ordem democrática. A globalização econômica, caracterizada pela desregularização financeira e abertura comercial, somada aos avanços tecnológicos, acentua de maneira significativa a desigualdade de renda em economias avançadas, auxiliando no aumento da distância econômica entre os trabalhadores e os super-ricos. A globalização cultural, por sua vez, contribui para a sensação de insegurança existencial de atores que - diante de fluxos migratórios compostos por indivíduos etnicamente e racialmente distintos - sentem que sua cultura está sob ameaça e que identificam que seus valores nacionalistas tradicionais estão sendo deslocados por valores progressistas pautados pelo cosmopolitismo e pelo multiculturalismo. Por fim, é reconhecida a pertinência da relação entre a globalização e a emergência de movimentos populistas, mas admite-se que um fenômeno tão complexo não possui uma causa exclusiva. Nesse sentido, deve-se exercitar a busca pela compreensão das frustações e insatisfações de parcela relevante do público eleitoral de países que foram sinônimo de estabilidade democrática e que hoje testemunham a ascensão de líderes autoritários.

Palavras-chave: Populismo, Globalização, Democracia liberal.

\section{Abstract}

The purpose of this article is to comprehend the rise of populism in western liberal democracies. With this in mind, we intend to examine the relationship between this phenomenon and the process of globalization. Therefore, after the comprehension of the basic features of populism, we analyze the ways in which globalization affects the domestic level. In doing so, two distinct dimensions of globalization are analyzed - the economic and the cultural dimensions - which will allow us to apprehend the role of economic and existential insecurity in the rise of political movements that defy the democratic order. The economic globalization, characterized by financial deregulation and commercial liberation, alongside the technological developments, greatly deepens income inequality in advanced economies, fomenting the economic distance between workers and the super-rich. Cultural globalization, on the other hand, reinforces the feeling of existential insecurity shared by people that, in the face of flows of immigrants racially and ethnically distinct from them, feel as if they were under a cultural threat, alongside the perception that their traditional values have been displaced by the progressist values based on cosmopolitism and multiculturalism. At last, we observe an important relationship between globalization and the rise of populism in western democracies, nevertheless, we acknowledge that such

\footnotetext{
* Este artigo é parte de pesquisa realizada pelo Programa de Bolsas de Iniciação Científica, Tecnológica e Inovação (PROBIC) da Pontifícia Universidade Católica de Minas Gerais sob a orientação da Dra. Maria de Fátima Junho Anastasia.

${ }^{1}$ Graduanda em Relações Internacionais na Pontifícia Universidade Católica de Minas Gerais (PUC-MG). Email: giovannamacieira7@gmail.com.
} 
a complex phenomenon cannot have a sole cause. Therefore, there is a need to make the effort to understand the frustrations of a significant share of the electoral public of countries that were once a model of democratic stability and that today witness the rise of authoritarianism.

Keywords: Populism, Globalization, Liberal democracy.

\section{Introdução}

O populismo, segundo Mudde (2004), constitui um fenômeno político caracterizado pela divisão antagônica da sociedade nacional entre um povo virtuoso e uma elite imoral. Esse fenômeno tem representado, no século XXI, uma ameaça substancial à estabilidade de democracias liberais ocidentais consolidadas, caracterizadas historicamente pela participação política popular por meio da representação e pela garantia de diretos e liberdades fundamentais. Tanto ao denunciar os trâmites institucionais característicos da democracia representativa quanto ao defenderem a ideia de que somente o líder populista estaria disposto a avançar os interesses do povo, o populismo termina por contestar a própria legitimidade do sistema representativo e da competição democrática.

Contudo, nos países aos quais esta pesquisa se dedicará - Estados Unidos e França - os movimentos populistas que emergiram no século XXI possuem um caráter sui generis e têm sido caracterizados singularmente por um agressivo discurso antiglobalização, que permite a divisão antagônica da sociedade por meio da denúncia de elites supostamente desvinculadas do interesse nacional. Essa dinâmica, por seu turno, torna-se possível uma vez que a globalização não possui os mesmos efeitos para todos os membros da comunidade nacional. Sendo assim, o propósito desse artigo consiste no exame da forma como a globalização, ao gerar perdedores e vencedores, provoca o estabelecimento de uma nova clivagem política caracterizada pela divisão entre aqueles que rejeitam e aqueles que apoiam o fenômeno.

Para tanto, serão analisados dois aspectos distintos da globalização - o aspecto econômico e o aspecto cultural. Essa divisão artificial de um processo complexo auxilia na apreensão das diferentes motivações por detrás do apoio de um segmento expressivo da população de democracias liberais à líderes e movimentos de caráter autoritário. Insegurança econômica e existencial constituem os dois lados da mesma moeda que permite a mobilização de parte significativa do público eleitoral pelo discurso populista de personagens como Donald Trump, nos Estados Unidos, e Marine Le Pen, na França. 
O populismo compreende um fenômeno político extremamente controverso e de difícil apreensão. Dessa forma, a primeira seção do artigo fora destinada ao entendimento desse fenômeno, suas características principais e seu modus operandi. Sendo assim, nessa seção serão examinadas características fundamentais do populismo como o antielitismo, o anti-pluralismo, sua relação com a democracia representativa e sua concepção particular do povo ao qual se dirige.

Em seguida, será analisada a forma por meio da qual a globalização estabelece uma nova clivagem política em torno da qual se mobilizarão os eleitores. Em primeiro lugar, serão analisadas as consequências econômicas da globalização. Desse modo, serão examinados os efeitos distributivos da liberalização financeira e comercial sobre o público doméstico, não deixando de lado o papel dos avanços tecnológicos sobre o crescimento vigoroso da desigualdade de renda em economias avançadas.

Em segundo lugar, serão examinados os impactos culturais da globalização sobre os atores domésticos. Aqui, tem-se os fluxos migratórios de indivíduos etnicamente e racialmente distintos das populações nativas de democracias ocidentais, que agravam a sensação de insegurança existencial de indivíduos que temem tornarem-se minorias em seu próprio território. Somado a isso, entende-se que uma parcela expressiva do eleitorado de democracias liberais sente que seus valores tradicionais - relacionados a família, nação e religião - estão sendo marginalizados diante do avanço de ideais progressistas. Esse segmento populacional enxerga com desconfiança o processo de globalização, entendido como um projeto de elites dissociadas de seus valores.

Por fim, conclui-se que o populismo e a ascensão de líderes autoritários não possuem uma causa única. A globalização, a mídia e mesmo características fundamentais da democracia liberal, que permitem sua existência no mundo moderno, auxiliam na emergência de movimentos de contestação. Sendo assim, as diversas tentativas de compreensão das insatisfações que levam indivíduos a apoiarem esses movimentos fazem-se todas fundamentais para enfrenta-lo.

\section{O Fenômeno Populismo}

O populismo certamente não constitui um fenômeno novo ou próprio do século XXI. A ascensão de líderes ou partidos que recorrem a antagonismos entre um povo homogêneo e uma elite corrupta ou imoral não são episódios incomuns na trajetória política moderna. O US 
People's Party ${ }^{2}$, nos Estados Unidos, e o movimento Poujadista ${ }^{3}$, na França, são exemplos da relevante expressão do populismo na política ocidental (Mudde, 2004). No entanto, a ascensão recente de movimentos populistas em democracias liberais compartilha como característica, não apenas a condenação das elites, mas, também, um feroz discurso antiglobalização (Zahra, 2016). Isso indica que estamos diante de um fenômeno singular que se fortalece desde o final século XX e que parece ter se estabelecido como um dos principais traços da dinâmica política no início do século XXI: esse novo fenômeno é o populismo como produto dos efeitos da globalização.

Diante da particularidade desses novos movimentos populistas que ameaçam a estabilidade de democracias liberais ocidentais consolidadas, faz-se necessário investigar os efeitos da globalização sobre os contextos políticos de países que, ao longo do tempo, serviram de exemplos de estabilidade democrática e institucional. Todavia, a fim de compreender os impactos da globalização sobre a ascensão de movimentos populistas nessas democracias fazse necessário, antes de avançar, compreender o que constitui esse notório fenômeno denominado populismo.

Segundo Albertazzi \& Macdonnel (2008), a definição de populismo consiste em uma tarefa desafiadora para a Ciência Política. A dificuldade em definir esse fenômeno está relacionada ao fato de que, ao contrário de rótulos como "socialista" ou "conservador" que foram minuciosamente definidos por seus proponentes, os populistas não se enxergam ou não se permitem enxergar como populistas. O termo é comumente utilizado por partidos ou políticos como uma forma de questionar ideias ou lideranças as quais eles se opõem. São raras as vezes nas quais um político se auto intitula populista; normalmente, a denominação populista serve apenas ao adversário. Nesse sentido, segundo Fracisco Panizza (2005), o termo populismo tem se estabelecido mais como uma categoria analítica do que como um termo com o qual os atores políticos voluntariamente se identificam.

Apesar da difícil tarefa que configura a definição da categoria populismo, há certas abordagens que certamente precisam ser evitadas. Cas Mudde (2004) argumenta que abordagens que apreendem o fenômeno populismo como um discurso emocional e simplório que objetiva a mobilização dos sentimentos dos eleitores ou como uma estratégia política oportunista devem ser evitadas. A delimitação do que seria um discurso sério ou simplório, racional ou emocional e do que seria uma estratégia oportunista ou uma estratégia pragmática,

\footnotetext{
${ }^{2}$ Criado no fim do século XIX, é considerado um dos movimentos populistas definidores (Mudde, 2004).

${ }^{3}$ O Pujadismo, fundado por Pierre Poujade na década de 50, foi um movimento populista anti-impostos e antimodernização (RydgrenN, 2008).
} 
apenas auxilia na mobilização do termo populista como ferramenta de contestação de ações ou atores políticos.

Ademais, Jen-Warren Müller (2016) defende que a limitação dos apoiadores de movimentos e lideranças populistas a um certo perfil socioeconômico ou psicológico, não apenas não auxilia na definição da categoria, mas dificulta o estudo e o entendimento de como lidar com a ascensão de movimentos populistas, podendo se autorestringir à prescrição de terapias políticas para curar ansiedades e ressentimentos. Aqui, faz-se importante reconhecer que ansiedades e ressentimentos podem existir, no entanto, se eles existem, existe também uma causa que deve ser apreendida - nesse artigo, parte-se da premissa de que essa causa estaria relacionada ao fenômeno da globalização.

A fim de compreender o populismo, precisamos reconhecer que esse fenômeno possui uma lógica interna que permite a organização imaginativa da sociedade de uma maneira específica e particular. Para Cas Mudde (2004), o populismo consiste em:

Uma ideologia que considera a sociedade como ultimamente separada entre dois grupos homogêneos e antagônicos, o 'povo puro` em oposição a uma elite corrupta, e que argumenta que a política deveria ser a expressão da volonté generale (vontade geral) do povo (Mudde, 2004, p. 543, tradução nossa) ${ }^{4}$.

Diante disso, temos o antielitismo como uma característica necessária do populismo, mas não suficiente, uma vez que nem toda crítica ao establishment ou ao status-quo é populista. O populismo é ainda invariavelmente antiplural. O pluralismo compreende a sociedade como uma “...coleção heterogênea de grupos e indivíduos com opiniões e desejos fundamentalmente diferentes"' (Mudde, 2004, p. 544, tradução nossa) ${ }^{5}$, enquanto o populismo compartilha uma visão maniqueísta de uma sociedade dividida entre um povo virtuoso e uma elite corrupta e imoral. Ademais, para os populistas, somente eles podem representar o povo, qualquer outro concorrente político é parte da elite imoral, desse modo, não existem oposição ou concorrentes legítimos (Müller, 2016).

O elemento central do populismo é, evidentemente, o povo, mesmo seu caráter antielitista deriva do antagonismo da elite em relação ao povo. A fim de compreendermos o conceito de povo articulado pelo populismo, precisamos reconhecer o caráter imaginativo e moralista atribuído ao povo e ao seu oposto - as elites. Os elementos centrais do populismo não

\footnotetext{
${ }^{4}$ No original: "[...] an ideology that considers society to be ultimately separated into two homogeneous and antagonistic groups, 'the pure people' versus 'the corrupt elite', and which argues that politics should be an expression of the volonté générale (general will) of the people" (Mudde, 2004, p. 543).

${ }^{5}$ No original: "[...] as a heterogeneous collection of groups and individuals with often fundamentally different views and wishes" (Mudde, 2004, p. 544).
} 
são contrapostos de maneira programática, em função de suas diferenças empíricas, seja no campo econômico, político ou cultural, as elites não constituem apenas um grupo com visões de mundo e opiniões diferentes. A elite, no discurso populista, é má e imoral, enquanto o povo, moralmente superior, precisa que seus valores e virtudes sejam defendidos e protegidos pelos populistas (Mudde, 2004).

Faz-se fundamental, no entanto, a compreensão de que, para o populismo, o povo não é um conceito que pressupõe uma sociedade inclusiva. A ideia de povo não corresponde empiricamente à população. Ainda segundo Mudde (2014):

[...] o povo, na propaganda populista, não é real e nem inclui a todos, mas representa, na realidade, um segmento mítico e construído da população. Em outras palavras, o povo, para os populistas, constitui uma 'comunidade imaginada', assim como a nação para os nacionalistas (Mudde, 2004, p. 546, tradução nossa). ${ }^{6}$

Sendo o povo virtuoso um grupo homogêneo, o populismo defende que a política não deveria mais ser dividida por diferentes competidores, ideologias, ideias ou programas. É possível e desejável que o povo seja uno e que, dessa forma, possua um verdadeiro e único representante: o líder populista (Müller, 2016). O populismo pressupõe a defesa do que Müller (2016) compreende como representação exclusiva. Essa representação é exercida, por sua vez, por um líder que, não necessariamente se compromete a incrementar a participação do povo na política, mas que, supostamente, entende o povo, seus valores e seus desejos. No contexto estadunidense, podemos observar claramente a operacionalização dessa dinâmica entre Trump e seus eleitores - uma relação pautada pela confiança, em que o líder não necessariamente se parece com o povo, mas o conhece e o compreende - seria a volta da corrente jacksoniana na política estadunidense (Mead, 2017).

Segundo Mead (2017), o Jacksonianismo, marcado pelo seu forte caráter populista nacionalista, fundamenta-se no pensamento do primeiro presidente populista estadunidense, Andrew Jackson. Para os jacksonianos, que compõem a base de apoio mais fiel de Donald Trump, os Estados Unidos constituiriam o Estado-Nação do "povo americano" - entendido como branco de ascendência anglo-saxônica. O caráter único dos Estados Unidos não estaria em sua vocação cosmopolita para transformar o mundo, mas sim em seu comprometimento com o bem-estar dos verdadeiros cidadãos estadunidenses. Nesse sentido, para esse grupo, a "América Jacksoniana" estaria sob a ameaça de elites não-patrióticas que, junto a minorias

\footnotetext{
${ }^{6}$ No original: "[...] the people in the populist propaganda are neither real nor all-inclusive, but are in fact a mythical and constructed sub-set of the whole population. In other words, the people of the populists are an 'imagined community', much like the nation of the nationalists” (Mudde, 2004, p. 546).
} 
étnicas, estariam tentando transformar o caráter essencial dos Estados Unidos. Assim, faz-se necessário um líder no qual os jacksonianos possam confiar, não apenas na sua capacidade, mas em seu compromisso patriótico com os interesses e valores dos "verdadeiros americanos".

Diante da defesa da representação exclusiva, podemos melhor entender de que forma o populismo não apenas representa uma ameaça à democracia representativa, mas, também, surge como sua sombra. Isso ocorre porque são justamente os procedimentos institucionais característicos da democracia representativa que suavizam os impactos diretos da população sobre as decisões do governo, produzindo a impressão de uma elite política desobrigada e fortalecendo, dessa forma, o discurso populista de necessidade de uma representação exclusiva dos interesses e valores do povo por um líder comprometido com suas vontades (Alvarez \& Dahlgren, 2016).

Neste estudo, entendemos o conceito de democracia por meio de suas manifestações empíricas, conforme proposto por Robert Dahl (2006). Desse modo, ao invés de definirmos a democracia como um ideal ou ideais que devem ser alcançados ou pelo menos maximizados como muitas vezes é proposto pela própria retórica populista ao recorrer a ideia de soberania absoluta do povo - essa pesquisa compreenderá a democracia por meio das oito condições, estabelecidas por Dahl, que permitem a otimização da democracia no mundo real. As sete primeiras condições referem-se ao período eleitoral - as três primeiras ao período da votação, as duas seguintes ao período pré-votação, a sexta e a sétima ao período pós-votação. A oitava condição refere-se ao período entre eleições. São elas:

1. Todos os membros da organização executam os atos que se presume que constituam a expressão das preferências entre as alternativas disponíveis (ex: votar).

2. Ao tabular essas expressões (votar), o peso conferido a escolha de cada indivíduo é idêntico.

3. A alternativa com maior número de votos é declarada a escolha vencedora.

4. Qualquer membro que busque um conjunto de alternativas, dentro das quais ao menos uma ele considere como preferível as alternativas previamente apresentadas, pode inserir suas alternativas dentre aquelas apresentadas como opções na votação

5. Todos os indivíduos possuem informações idênticas sobre cada alternativa.

6. Alternativas (líderes ou políticas) com maior número de votos desbancam qualquer alternativa com menor número de votos.

7. As ordens dos oficiais eleitos são executadas.

8.1 Todos as decisões intereleitorais estão subordinadas aquelas que foram decididas no período eleitoral, assim, as eleições acabam servindo como um controle.

8.2 Ou que todas as decisões durante o período

intereleitoral serão governadas pelas sete condições 
anteriores, operando sobre circunstâncias institucionais diferentes.

8.3 Ou as duas condições acima (DAHL, 2006, p. 67-71, tradução nossa $)^{7}$

Se, para Dahl (2006), a democracia deve ser apreendida por meio da forma como ela se manifesta no mundo real, tem-se que a partir do século XIX, a forma de democracia que permeia o contexto político ocidental passa a ser a democracia representativa. Conforme descrito por Bobbio, Metteucci e Pasquino:

[...] a participação do poder político, que sempre foi considerada o elemento caracterizante do regime democrático, é resolvida através de uma das muitas liberdades individuais que o cidadão reivindicou e conquistou contra o Estado absoluto. A participação é redefinida como manifestação daquela liberdade particular que indo além do direito de exprimir a própria opinião, de reunir-se ou de associar-se para influir na política do país, compreende ainda o direito de eleger representantes para o Parlamento e de ser eleito (Bobbio et al., 1983, p. 324).

Conforme irá expor Bobbio (1988), a política representativa, que constitui o grande alvo da retórica populista, se estabelece por meio da prevalência das liberdades individuais que se materializam a partir da segurança das garantias privadas dos indivíduos. Por outro lado, no que concerne a democracia direta - constantemente fantasiada pela retórica populista - tem-se, em detrimento das liberdades individuais, a prevalência das liberdades coletivas que se referem à distribuição igual do poder político a todos os cidadãos e está, em grande medida, vinculada a ideia de "vontade geral" de Rousseau, a partir da qual a agregação das vontades particulares dos indivíduos seria representada pelo Estado por meio da democracia direta. Dessa forma, temse que as liberdades individuais e as liberdades coletivas estão em oposição, pois, "a participação direta nas decisões coletivas termina por submeter os indivíduos à autoridade do todo e por torna-lo não livre como privado" (Bobbio, 1988, p. 8).

\footnotetext{
${ }^{7}$ No original: "1. member of the organization performs the acts we assume to constitute an expression of preference among the scheduled alternatives, e .g., voting; 2 . In tabulating these expressions (votes), the weight assigned to the choice of each individual is identical; 3 . The alternative with the greatest number of votes is declared the winning choice; 4 . Any member who perceives a set of alternatives, at least one of which he regards as preferable to any of the alternatives presently scheduled, can insert his preferred alternative(s) among those scheduled for voting; 5 . All individuals possess identical information about the alternatives; 6 . Alternatives (leaders or policies) with the greatest number of votes displace any alternatives (leaders or policies) with fewer votes; 7. The orders of elected officials are executed; 8.1. Either that all interelection decisions are subordinate or executory to those arrived at during the election stage, i.e., elections arc in a sense controlling; 8.2. Or that new decisions during the interelection period are governed by the preceding seven conditions, operating, however, under rather different institutional circumstances; 8.3. Or both" (Dahl, 2006, p. 67-71).
} 
A retórica populista elucida que a democracia representativa teria fracassado em virtude de elites políticas e burocráticas - estejam elas no nível nacional, internacional ou supranacional - que perpetuam a corrupção. Além disso, os populistas defendem que os trâmites institucionais característicos da democracia representativa em países ocidentais seriam instrumentos elaborados com o intuito de frustrar a vontade popular e impedir a participação efetiva do povo na política (Albertazzi \& MacDonnel, 2008). Nesse sentido, o populismo, enquanto retórica, afirma ser o salvador da verdadeira democracia e da soberania do povo, enquanto na prática, corrói as normas e instituições que permitem a existência da democracia no mundo moderno.

A fim de construir a ideia de um povo homogêneo, puro e virtuoso, a contraposição desse segmento mítico da população à uma elite corrupta não é suficiente. O conceito de povo para o populismo, uma vez que, não inclui toda população, pressupõe a contraposição do povo virtuoso a um outro - se o povo é reconhecido por sua pureza existe aquele que não faz parte dele, o outro. A premissa de que apenas algumas pessoas fazem parte do povo é fundamental ao populismo (Müller, 2016). Dessa forma, temos elementos recorrentes na retórica populista como "o verdadeiro povo", "o povo de verdade", "o povo comum" e outras inúmeras delimitações abstratas que evidenciam o caráter excludente da ideia de povo.

Diante disso, os populistas inferem que o povo estaria sendo atacado de cima pelas elites e de baixo pelo outro, que também pode ser entendido aqui como constituindo as minorias (Albertazzi \& MacDonnel, 2008). Segundo os populistas, haveria uma espécie de aliança entre as elites e as minorias que estariam conspirando contra o povo virtuoso. O povo precisaria então ser protegido por seu líder populista que invoca a necessidade do reestabelecimento da ordem natural das coisas, a volta de um passado no qual o povo virtuoso ainda era soberano (Albertazzi \& MacDonnel, 2008).

Nesse sentido, a fim de compreender a reinvindicação populista de volta ao passado, precisamos compreender o presente, isto é, o contexto no qual a ascensão de movimentos populistas ocorre. Segundo Nye (2017), a ampliação de movimentos populistas de extremadireita em democracias liberais ocidentais possui suas raízes, não apenas nas estruturas desses regimes políticos, mas, também, em fenômenos advindos de eventos que ocorrem no nível internacional, como a má distribuição dos ganhos da globalização e o sentimento de ameaça cultural em virtude da exposição das massas ao multiculturalismo e de uma eventual perda de preponderância demográfica dos brancos nos Estados Unidos e na Europa. Assim, a ascensão desses movimentos deve ser apreendida como uma reação contrária à globalização que, segundo os líderes desses movimentos, seria um projeto de elites cosmopolitas (Nye, 2017). 
A globalização teria solapado a ordem natural das coisas. Portanto, a compreensão desse contexto faz-se fundamental para apreender o processo de construção imaginativa do povo e seus antagonistas - elites e minorias - nos países ocidentais, assim como para o entendimento da relevância do caráter antiplural desses movimentos.

O presente artigo abrange o estudo dos efeitos da globalização sobre a recente evolução de movimentos populistas de extrema-direita. Contudo, faz-se importante ressaltar que o populismo não é entendido como um fenômeno político articulado apenas pela extrema-direita. A defesa do povo como o único soberano legítimo e a crítica à uma elite que haveria supostamente ocupado o lugar desse na política são elementos fundamentais da retórica populista e que podem ser mobilizados tanto pela esquerda quanto pela direita (Albertazzi \& MacDonnel, 2008). Todavia, segundo Cas Mudde (2004), ao final do século XX e especialmente no início do século XXI, temos, em democracias liberais ocidentais, a prevalência da ascensão de partidos, movimentos e líderes populistas de extrema-direita - como o FPÖ de Jörg Haider na Aústria, o LPF de Pim Fortuyn na Bélgica, o Rassemblement National na França e, mais recentemente, Donald Trump nos Estados Unidos (Mudde, 2004). Essa predominância, por sua vez, está fortemente relacionada ao caráter nacionalista da direita radical, podendo o imaginário de nacional e povo se confundirem facilmente (Mudde, 2004).

Por fim, a globalização, entendida como um projeto das elites cosmopolitas, constitui o contexto ideal para a evocação de uma ameaça aos valores, às necessidades, aos desejos e ao modo de vida do povo virtuoso e o aumento dos fluxos migratórios em direção ao Ocidente acentua essa percepção de ameaça. Ademais, além de constituir uma importante ferramenta simbólica para ascensão do populismo, a globalização possui efeitos econômicos relevantes sobre as economias nacionais que, quando mobilizados de maneira estratégica, constituem um segundo motor para a ascensão de movimentos populistas.

\section{A globalização e o espaço de competição política nacional}

O presente artigo entende que não é mais possível compreender a dinâmica política doméstica dos Estados sem apreender sua relação com o nível internacional. A ascensão do populismo em democracias liberais ocidentais no final do século XX e início do século XXI é caracterizada por constantes questionamentos à Ordem Liberal Internacional que se estabeleceu após a Segunda Guerra Mundial e por uma agressiva campanha antiglobalização. Notadamente, esses questionamentos advêm, não apenas de países que foram de alguma forma excluídos durante o processo de globalização ou durante a construção dessa nova Ordem, mas, também, 
de países que protagonizaram o fomento do processo de globalização e a construção do novo ordenamento.

Diante do propósito de investigar os efeitos da globalização sobre o espaço de competição política $^{8}$ doméstico, faz-se fundamental a distinção entre os dois lados que compõem o processo democrático durante o período eleitoral - o lado da demanda e o lado da oferta (Kriesi et al., 2008). O primeiro corresponde aos eleitores que buscam, por meio do voto, avançar seus interesses e reinvindicações, o segundo corresponde aos políticos ou partidos políticos que, por meio da mobilização do eleitorado e de suas respectivas preferências, almejam a vitória eleitoral. Tendo isso em vista, este artigo consiste no exame dos efeitos da globalização sobre o lado da demanda, isto é, o exame de como a globalização influi sobre a formação das preferências dos eleitores.

A fim de compreender os efeitos da globalização sobre o público doméstico de democracias liberais ocidentais, tem-se que os efeitos desse processo não são os mesmos para todos os membros da comunidade nacional. Dessa forma, esse fenômeno contribui para o estabelecimento de uma nova clivagem política em democracias liberais, caracterizada pela divisão entre os grupos que apoiam e os grupos que rejeitam esse processo. Essa nova clivagem pode ser dividida em duas dimensões - uma econômica e outra cultural - que, comumente, mas não necessariamente, andam juntas, isto é, o ator que rejeita (ou apoia) a globalização econômica, não necessariamente rejeita (ou apoia) a globalização cultural (KRIESI et al., 2008). Os líderes e partidos populistas, por sua vez, mobilizarão, por meio de uma forte campanha antiglobalização, os atores domésticos que rejeitam o fenômeno.

A globalização, como um processo amplo, pode ser apreendida como "um processo de desnacionalização que levou ao encolhimento das fronteiras nacionais" 9 (Kriesi et al., 2008, p. 3, tradução nossa). No entanto, faz-se necessário a compreensão de dois aspectos distintos da globalização - o econômico e o cultural.

Ao examinar os impactos da globalização sobre o lado da demanda no processo democrático, isto é, sobre o público que compõe o eleitorado, tem-se que a ideia de que a

\footnotetext{
${ }^{8}$ Por espaço político se entende a área de conflito que constitui a base da relação entre eleitores e partidos, num dado sistema político e num certo momento histórico. Todo sistema político é caracterizado por um certo número de conflitos: conflitos sobre a distribuição da renda, sobre a intervenção do Estado na economia, sobre as relações Estado-Igreja, ou então conflitos de natureza linguística, étnica, e por aí além. Na medida em que tais conflitos ou linhas de divisão são fatores de mobilização do eleitorado, eles influem no comportamento político dos eleitores e na estratégia dos partidos e, consequentemente, no desenrolar da disputa eleitoral. A conformação destes conflitos representa a área do Espaço político. Em resumo, portanto, o Espaço político identifica-se com o espaço da competição eleitoral nos regimes democráticos de massa (Bobbio et al., 1983, p. 392).

${ }^{9}$ No original: "as processes of 'denationalization' (Beisheim et al. 1999; Zürn 1998), i.e. as processes that lead to the lowering and 'unbundling' of national boundaries" (Kriesi et al., 2008, p.3).
} 
insegurança econômica está relacionada a mudanças profundas na força de trabalho e na vida econômica das sociedades pós-industriais diante de um contexto de globalização (Inglehart \& Norris, 2016). Ademais, a noção de um cultural backlash é também consequência de uma forma de insegurança, por sua vez, existencial - uma parcela da população de países ocidentais que se identifica mais fortemente com valores tradicionais familiares sentem que seus valores, uma vez predominantes, estão sendo substituídos por valores pós-materialistas associados a ideais como cosmopolitismo, multiculturalismo e direitos humanos compartilhados por uma parcela da população que, além disso, concede espaço para manifestações culturais de minorias étnicoraciais (Inglehart \& Norris, 2016).

Aqui, segundo Inglehart \& Norris (2016), faz-se importante ainda destacar que a distinção dos impactos econômicos e culturais da globalização e, de uma maneira geral, da modernidade, sobre o espaço de competição política de democracias liberais ocidentais possui um caráter artificial. Dessa forma, é fundamental o reconhecimento de que normalmente os dois efeitos agem em conjunto e, muitas vezes, se reforçam. No entanto, essa diferenciação serve aos desígnios analíticos desse artigo.

No que tange ao aspecto econômico da globalização, o grau de abertura comercial e financeira dos países cresceu após a Segunda Guerra Mundial diante dos novos arranjos internacionais que caracterizariam o período pós-guerra (Ikenberry, 2010). Segundo Rodrik (2018), o pensamento keynesiano que delineou os arranjos econômicos após as guerras compreendia que para a construção de uma economia mundial favorável ao comércio e as finanças internacionais seria necessário o estabelecimento de controles macroeconômicos que possibilitariam a gerência dos fluxos financeiros e comerciais. O sistema resultante desse raciocínio é o denominado sistema Bretton Woods, composto pelo Fundo Monetário Internacional (FMI) e pelo Banco Mundial. Os princípios que norteiam essas instituições foram aplicados posteriormente, em 1947, ao Acordo Geral de Tarifas e Comércio (GATT) que, estabelecido com o objetivo de promover o comércio mundial, será substituído em 1995 pela Organização Mundial do Comercial (OMC) (Rodrik, 2018).

Conforme discutido por Rodrik em um estudo anterior (2010), a ideia por trás do sistema estabelecido em 1944 e que viria a reger a economia mundial durante as três décadas posteriores era pragmática e realista. A fim de promover o livre comércio e a abertura econômica dos Estados de uma forma sustentável, fazia-se necessário permitir que os governos pudessem aderir a esse novo mundo sem deixar de responder a imperativos sociais e econômicos domésticos - como desemprego, segurança social e igualdade econômica. Tendo isso em vista, 
os controles macroeconômicos assumiram um papel fundamental para o sucesso do sistema Bretton Woods e do comércio internacional. Iniciou-se então um longo processo de integração econômica que, no entanto, ainda permitia aos Estados protegerem pautas sociais e setores econômicos sensíveis (Rodrik, 2010).

O novo sistema contribuiu para o crescimento expressivo do comércio e investimento internacional, permitindo um rápido crescimento das economias mundiais (Rodrik, 2018). Contudo, a partir da década de oitenta, as instituições Bretton Woods e, de maneira mais ampla, o sistema econômico internacional tornaram-se vítimas do seu próprio sucesso. Conforme evidenciado por Rodrik:

A partir da década de 1980, tomadores de decisão e economistas pensaram que poderiam fazer o sistema funcionar ainda melhor ao pressionar por uma integração econômica mais profunda. Acordos comerciais se tornaram mais ambiciosos, indo além das fronteiras e interferindo em regulações domésticas. A remoção das restrições sobre mobilidade de capitais deixou de ser exceção para tornar-se a norma (RODRIK, 2018, p. 27, tradução nossa). ${ }^{10}$

Tradicionalmente, as possibilidades de investimento em mercados financeiros e bolsas de valores estrangeiros eram muito limitadas. Os países eram favoráveis a multinacionais ou a investimentos internacionais de longo-prazo nas cadeias produtivas, no entanto, o denominado investimento de curto-prazo, isto é, os fluxos de portfólio, eram vistos como fonte de instabilidade. Dessa forma, os governos estabeleciam uma série de restrições e controles sobre a mobilidade de capital. Além disso, desde a fundação do sistema Bretton Woods, o consenso dentro das instituições era o de que, a fim de se estabelecer um crescimento econômico real, a mobilidade de capital deveria ser limitada (Rodrik, 2010).

A partir de 1980, no entanto, o consenso que havia predominando no sistema econômico internacional por mais de trinta anos seria substituído pelo seu oposto, a liberalização do mercado de capitais tornou-se então a nova norma. A crença estipulava que a maior mobilidade de capitais inauguraria uma nova era de crescimento econômico pois permitiria a alocação das poupanças globais de maneira mais eficiente (Rodrik, 2010). Supreendentemente, nem mesmo a crise asiática que, em virtude de uma inesperada fuga de capital, afligiu o mercado financeiro de países da região como Indonésia, Malásia, Filipinas, Tailândia e Coreia do Sul e reverberou de forma catastrófica em países como Rússia e Argentina no final da década de 90, foi capaz

\footnotetext{
${ }^{10}$ No original: "By the late 1980s, policy makers and economists thought they could make it work even better by pushing for deeper economic integration. Trade agreements became more ambitious and reached beyond the border into domestic regulations. The removal of restrictions on capital mobility became the norm rather than the exception" (Rodrik, 2018, p. 27).
} 
abalar a nova doutrina que regia o FMI e Banco Mundial (Rodrik, 2010). Havia sido determinado, quanto mais liberalização, maior o crescimento. Até que em 2008 uma nova crise colocaria a prova qualquer desconfiança em relação aos limites da liberalização econômica.

A desregularização do sistema financeiro que se iniciou na década de 80 estabeleceu as fundações para a crise econômica que eclodiu em 2008. A crise se iniciou em virtude da especulação financeira em torno das hipotecas nos Estados Unidos. Contudo, os eventos que levaram a sua eclosão são ainda mais abrangentes. Segundo Thirkell-White (2009), diante do aprofundamento de desequilíbrios comerciais globais a partir da virada do milênio, o governo estadunidense recorreu a uma menor taxa de juros como ferramenta para moderar esses desajustes. As instituições bancárias, por sua vez, diante de taxas de juros cada vez mais baixas, recorreram a inovações financeiras cada vez mais arriscadas, como o mercado de hipotecas, para conseguirem manter suas receitas. Quando o não pagamento dos empréstimos hipotecários que estimulavam o mercado se tornou comum, não havia dúvida de que as práticas financeiras não eram sustentáveis, desse modo, os empréstimos tornaram-se cada vez mais escassos e a economia estadunidense entrou em recessão (Thirkell-White, 2009).

No entanto, a crise não se limitou aos Estados Unidos. Um ambiente financeiro cada vez mais desregulado e permeado por práticas e instituições não convencionais garantiu a magnitude estrondosa da recessão que, ocorrendo dentro de um sistema internacional também caracterizado pela condenação dos controles sobre fluxos de capitais, espalhou-se rapidamente para outras economias (Thirkell-White, 2009).

A crise de 2008 é significativamente responsável pelo sentimento de desamparo e insegurança econômica que permitiu a ascensão de movimentos populistas no cenário político de democracias liberais ocidentais. A crise inaugura uma nova era marcada por baixo crescimento econômico e altas taxas de desemprego nos países afetados, dentre eles, Estados Unidos e França. Contudo, segundo Paul Krugman (2013), não apenas as consequências diretas da crise, mas, também, respostas erradas ao evento agravaram seus efeitos. Os governos, ao invés de apoiarem a demanda por meio de uma política fiscal expansionista, orientados por um novo imperativo econômico em torno da austeridade, contraíram os gastos em busca de uma suposta confiança do mercado e, não apenas prolongaram a recessão, como, também, aprofundaram seus efeitos distributivos e sociais (Krugman, 2013).

A desigualdade doméstica, no entanto, não deve ser entendida como uma função exclusiva da crise e das respostas que a procederam, apesar de ter sido notoriamente agravada pelo evento. Os problemas distributivos que assolam as economias ocidentais são mais antigos. 
A desregularização financeira que vinha ocorrendo desde 1980, já abria o caminho para o aumento da desigualdade de renda em países como Estados Unidos e França, uma vez que as empresas passaram a buscar o lucro por meio de ações e outros mecanismos financeiros, substituindo o aumento do lucro por meio de um aumento na produção (Thirkell-White, 2009). Ademais, diante da liberalização do mercado de capitais tem-se a rendição dos governos aos imperativos do mercado em busca de investimentos de portfólio, isto é, de curto prazo, ao invés de investimentos de longo-prazo na cadeia produtiva que estimulam a economia de forma sustentável por meio da geração de empregos e, consequentemente, renda para a classe média (Rodrik, 2010).

Dentre os aspectos econômicos da globalização, não somente a liberalização financeira possui consequências distributivas, o comércio internacional também impacta de maneira significativa sobre a renda e as possibilidades econômicas dos elementos da comunidade nacional. A abertura econômica de um país possui consequências distributivas, gerando perdedores e vencedores, em qualquer cenário onde a mobilidade dos trabalhadores entre indústrias e entre regiões é limitada (Rodrik, 2018). Dessa forma, tem-se que qualquer análise empírica dos efeitos da abertura econômica envolve o reconhecimento de que o comércio internacional não será benéfico para todos.

Existem diferentes formas de analisar os efeitos do comércio internacional sobre a comunidade nacional. É possível, por exemplo, o exame dos impactos entre diferentes fatores de produção, nesse modelo, o fator de produção usado de maneira intensiva para a produção de produtos que, diante da abertura, tornaram-se importáveis, experimentam um declínio da renda. Assim, em economias avançadas, trabalhadores menos qualificados sofrem perdas expressivas, enquanto trabalhadores mais bem qualificados, que compõem o fator de produção utilizado de maneira intensiva para a produção de bens exportáveis, são beneficiados durante o processo de abertura (Rodrik, 2018).

Ademais, pode-se analisar também os impactos distributivos do comércio, não por fator de produção, mas por setor econômico, conforme evidenciado por Kriesi et al. (2008). Segundo o autor, atores vinculados a setores alinhados as vantagens comerciais do país tendem a apoiar o processo de liberalização econômica, enquanto os atores vinculados a setores que não são bem-sucedidos em um cenário de competição internacional, tendem a pressionar por mais barreiras protecionistas. Por fim, a conclusão primordial é: o comercial internacional produz vencedores e perdedores. 
Ademais, em se tratando do processo de abertura comercial, tem-se ainda a sombra da desindustrialização. Indústrias podem simplesmente deixar de existir em países onde não estão alinhadas as vantagens comerciais. Os custos de produção tornam-se excessivos se comparados a outras partes do mundo e, dessa forma, as indústrias, que possuem maior mobilidade do que os trabalhadores, se alocam em países onde a mão-de-obra, por exemplo, seja mais barata. Assim, tem-se um rápido processo de desindustrialização de economias avançadas (Rodrik, 2018).

No entanto, a abertura comercial e a liberalização financeira não são os únicos responsáveis pelo aumento da desigualdade de renda em economias avançadas. Na realidade, os avanços tecnológicos devem assumir, também, uma parcela razoável de responsabilidade pelo crescimento da desigualdade e aumento das taxas de desemprego em países da Europa e nos Estados Unidos (Rodrik, 2018). Segundo relatório da Organização para a Cooperação e Desenvolvimento Econômico (OCDE) (2018), os avanços tecnológicos possuem consequências distributivas profundas. A tecnologia substitui alguns postos de trabalho, mas, também, cria possibilidades, entretanto, as competências dos trabalhadores que perderam seus empregos em função da automatização não são as mesmas exigidas para os novos postos.

Ainda segundo o relatório, as consequências distributivas dos avanços tecnológicos são percebidas também por meio da comparação regional. Os novos postos de trabalho, advindos dos avanços tecnológico, estão concentrados em regiões especificas, geralmente próximas aos grandes centros financeiros, contribuindo assim para o aumento da desigualdade regional dentro de economias avançadas (OCDE, 2018). Dessa forma, a automatização e a digitalização resultam na polarização do emprego, gerando, assim como a globalização, perdedores e vencedores.

Em síntese, o World Inequality Report (2018), evidência as consequências mais notáveis da globalização e dos avanços tecnológicos sobre as economias ocidentais avançadas. Em geral, a classe média desses países tem diminuído e empobrecido relativamente aos mais ricos, realidade exposta por uma menor participação na renda nacional. Enquanto isso, os 1\% ou 10\% mais ricos têm aumentado sua riqueza de maneira desmedida. Dessa forma, tem-se uma inversão da participação na renda nacional e um aumento expressivo da distância entre os trabalhadores e os super-ricos. Esse fenômeno ocorre notadamente em função do aumento do lucro por meio do mercado de capitais, automatização e informatização das cadeias produtivas, somada a liberação comercial, conforme exposto até então. 
Tendo em vista as consequências distributivas da globalização e dos avanços tecnológicos, tem-se como fundamental o reconhecimento do papel da insegurança econômica sobre a ascensão de movimentos populistas em economias avançadas. Conforme pesquisa publicada pelo Pew Research Center (2019), pessoas com uma visão pessimista em relação à economia, tendem a estar mais insatisfeitas com a forma como a democracia funciona, ademais, são justamente as pessoas insatisfeitas com a democracia que compõe a base de apoio de partidos populistas. Aqui faz-se importante ressaltar que, os atores domésticos que apoiam populistas não precisam necessariamente terem sido os maiores prejudicados durante o processo de globalização e modernização - apesar de muitas vezes o serem - apenas precisam ser convencidos pelo discurso populistas e acreditar que essa é a realidade e, dessa forma, se mobilizarem em torno da rejeição desses fenômenos.

Segundo Rodrik (2018), a mensuração da parcela culpa que caberia a desregularização financeira, a liberalização comercial ou aos avanços tecnológicos consiste em uma tarefa impossível. No entanto, em meio a tantos fatores que acentuam a desigualdade de renda em economias avançadas, o discurso populista elegeu o grande culpado - o comércio internacional. O populismo não responde ao problema da desigualdade com propostas políticas pragmáticas, pelo contrário, as frustações daqueles que não conseguiram acompanhar os avanços da globalização e da modernidade são canalizadas em uma direção programática específica por meio de uma narrativa simples (Rodrik, 2018). Dessa forma, o discurso populista fornece respostas óbvias a um público que precisa escutá-las, são soluções simples para problemas complexos - "é isso que está acontecendo e é assim que vamos combater os responsáveis".

Uma campanha eleitoral estruturada em torno da culpabilização e condenação dos avanços tecnológicos evidentemente não possui um grande potencial de sucesso. Por outro, lado uma campanha baseada na denúncia de inimigos específicos - como China, México ou "estrangeiros que roubam o trabalho do povo" - provou-se enormemente capaz de alcançar resultados extraordinários.

Até o momento, está claro que a insegurança econômica e os efeitos distributivos da globalização são fatores relevantes para o estabelecimento de uma nova clivagem política em economias avançadas. No entanto, se as razões para a evolução do populismo em democracias liberais ocidentais fossem puramente econômicas, seria esperado uma mobilização em torno da clivagem tradicional de classe (Rodrik, 2018). Contudo, o que foi observado foi que os candidatos e partidos que buscaram mobilizar o eleitorado por meio dessa clivagem - Bernie Sanders nos Estados Unidos e Jean-Luc Mélenchon, do Partido Comunista, na França - não 
foram tão bem-sucedidos quanto os candidatos populistas de extrema-direita - Donald Trump e Marine Le Pen - que fizeram uso de um discurso nativista como carro chefe de suas campanhas.

$\mathrm{Na}$ realidade, se a clivagem fosse puramente econômica, o mundo poderia então ter testemunhado a ascensão do populismo de esquerda ao invés do populismo de direita. Entretanto, não foi isso que se sucedeu. O populismo de direita, caracterizado por um discurso xenofóbico e racista, ocupou o lugar disponibilizado pela nova clivagem política em torno da globalização. Tendo isso em vista, faz-se fundamental o entendimento das consequências culturais da globalização e da modernidade sobre os elementos da comunidade nacional de países como Estados Unidos e França que encontram no discurso populista a ressonância de seus ensejos.

As consequências culturais da globalização devem ser apreendidas a partir de dois polos distintos - um polo corresponde as minorias e o outro polo corresponde as elites e seus valores. No que se refere as minorias, faz-se necessário o entendimento dos efeitos culturais dos novos fluxos migratórios originários do sul global e compostos por indivíduos etnicamente distintos da população branca de democracias liberais ocidentais (Kriesi et al., 2008). No tocante as elites, por sua vez, têm-se a impressão, por parte do eleitorado, de que seu país estaria sendo conduzido por elites cosmopolitas, desvinculadas da realidade e dos valores tradicionais da nação (Nye, 2017). Somado a isso, os valores compartilhados, não apenas pelas elites, mas por grande parte da nova geração e por indivíduos provenientes dos grandes centros urbanos, estariam deslocando os valores tradicionais, uma vez predominantes, compartilhados por atores domésticos mais conservadores. Assim, tem-se uma parte expressiva do eleitorado que foi lentamente se tonando estranha aos valores cosmopolitas predominantes em seus países (Inglehart \& Norris, 2016).

Fluxos migratórios não são exclusivos ao processo de globalização que se estabeleceu a partir do pós-guerra e se aprofundou ao longo do tempo, ademais, não é tanto a intensidade desses fluxos, mas sim sua origem que determina as reações que os sucederão (Alesina et al., 2018). É evidente que em momentos de recessão econômica o número de imigrantes constitui fonte de apreensão, no entanto, imigrantes originários de locais cultural e etnicamente distantes das comunidades nacionais que adentram constituem um problema maior em torno do qual se mobilizam indivíduos que se sentem culturalmente ameaçados (Kriesi et al, 2008). Dessa forma, faz-se importante destacar que, se durante a Guerra Fria os fluxos migratórios e mesmo de refugiados eram, em grande parte, originários do leste europeu, diante do longo processo de 
descolonização que se iniciou em diversos países do sul global na década de 60, os fluxos de indivíduos se tornam cada vez mais culturalmente diversificados (Feller, 2001).

Diante desses novos fluxos, tem-se uma parcela expressiva da população de democracias liberais ocidentais que se sente culturalmente ameaçada. São indivíduos que sentem que, com passar dos anos, estão se tornando minorias em seu próprio país. No entanto, essa não é apenas uma questão numérica, tem-se o apoio significativo, a movimentos populistas, de parte de uma população branca que sente ter perdido seu status e privilégio em função da ascensão social de outros grupos demográficos (Nye, 2019). Assim sendo, pode-se imaginar a insatisfação e incredulidade desse grupo nos Estados Unidos diante do governo de um presidente etnicamente e racialmente distinto de seus predecessores, como o foi Barack Obama.

A suposta ameaça cultural representada pelas minorias étnicas e raciais, no entanto, não é único aspecto dos efeitos culturais da globalização que mobilizará o eleitorado em torno do fenômeno. Se as minorias, supostamente, atacam por baixo, as elites, por sua vez, investem contra o povo por cima (Mudde, 2004). Sendo assim, Rodrik (2018) propõe a divisão da sociedade em três grupos distintos: a elite, a maioria e a minoria. A elite é separada do restante em virtude de seu status econômico. A minoria, por sua vez, é separada da maioria em função de suas características étnicas e raciais. Contudo, nessa pesquisa compreende-se que, conforme proposto por Inglehart \& Norris (2016), as elites, e não apenas elas, mas, também, uma parcela significativa da população que comumente habita os grandes centros urbanos, também se diferencia devido a valores pós-materialistas distintos daqueles compartilhados pelo segmento mais conservador do eleitorado.

Em 1996, em O Choque de Civilizações e a Recomposição da Ordem Mundial, Samuel Huntington estabelece que, diante do fim da Guerra Fria, conflitos de ordem cultural substituiriam os conflitos de ordem ideológica que até então haviam sido predominantes. Contudo, Huntington argumenta que esses conflitos de caráter identitário/civilizacional ocorreriam entre Estados, não imaginando que esses conflitos pudessem ocorrer dentro dos próprios Estados e muito menos que esses conflitos colocariam a democracia liberal, para ele característica definidora da identidade ocidental, sob séria ameaça.

É justamente esse conflito de valores que permitirá que os populistas mobilizem seu eleitorado a partir da construção da ideia de uma elite cosmopolita, hostil aos valores tradicionais e fundamentais do povo e aliada as minorias culturais que "invadem" seus países e perturbam a ordem. Nos Estados Unidos, por exemplo, os Jacksonianos que compõem, conforme elaborado anteriormente, o eleitorado mais fiel de Donald Trump, foram convencidos 
de que a imigração seria uma estratégia das elites cosmopolitas para marginaliza-los em seu próprio país (Mead, 2017).

Nesse sentido, a retórica antielitista populista, conforme elucidado por Mudde (2004), é caracterizada por suas constantes denúncias de uma aliança entre as elites e as minorias, nesse caso raciais ou étnicas, contra o povo virtuoso. Tal retórica mobiliza vigorosamente os sentimentos e insatisfações de um eleitorado que sente ter sido deixado de lado ao longo do processo de globalização - aqui, o aspecto econômico da globalização influi de maneira expressiva sobre essa percepção de abandono.

Por fim, em vista dos efeitos culturais da globalização sobre o público doméstico nacional, faz-se possível compreender o apelo do discurso nativista e xenofóbico do populismo de extrema direita a um segmento específico, mas, ainda assim, expressivo da população ocidental. O populismo oferta a essa parcela da população, que pode ser compreendida como protecionista cultural, o monoculturalismo em detrimento do multiculturalismo, o interesse nacional em detrimento do cosmopolitismo e uma proposta de retorno aos valores tradicionais familiares em detrimento de ideais progressistas (Inglehart \& Norris, 2018). O discurso populista oferece uma segurança existencial a um público que acredita ter sido deixado de lado durante do processo de avanço da globalização e da modernização econômica.

\section{Considerações Finais}

O discurso populista promete a volta de um passado glorioso a um segmento populacional que acredita não possuir lugar na proposta de um futuro cosmopolita. Ansiedades econômicas e existenciais, uma vez mobilizadas por líderes autoritários populistas colocam sob ameaça mesmo as instituições democráticas mais bem consolidadas do mundo moderno, como é o caso dos Estados Unidos, Inglaterra e França. Sendo assim, a globalização e os valores vinculados a ela constituem um importante motor para a ascensão dos movimentos populistas que desestabilizam o cenário político de democracias liberais ocidentais. No entanto, faz-se imprescindível o reconhecimento de que um fenômeno tão complexo como o populismo não possui uma causa única e exclusiva.

Conforme elaborado no início desse estudo, as próprias características da democracia representativa asseguram espaço para a emergência de movimentos pautados na contestação do jogo democrático. O constitucionalismo liberal e a representação política que permitem a existência da democracia no mundo moderno, amortecem o impacto direto da população sobre o governo, o que pode constituir um elemento de frustração em relação as elites políticas e as 
instituições democráticas (Alvares \& Dahlgren, 2016). Essa insatisfação constitui um elemento fundamental para a mobilização do eleitorado populista a partir da ideia de soberania absoluta do povo que seria, por sua vez, garantida pelo líder populista que compreende suas vontades e desejos.

Ademais, a mídia também possui um papel essencial para a ascensão de movimentos populistas. Segundo Albertazzi \& Macdonnel (2008), em meio a competição por espectadores, a mídia tradicional sucumbe muitas vezes a cobertura extensiva de casos de corrupção e dos aspectos mais escandalosos da política, somado a abordagem emocional de problemas como segurança, desemprego e imigração. Assim, acaba contribuindo para um mal-estar e para um sentimento antipolítica que servirá posteriormente aos discursos populistas. Além disso, a própria crítica da mídia tradicional pode servir aos objetivos de líderes populistas que se valem das constantes condenações para a construção da imagem de um underdog ou um outsider. Por outro lado, as novas mídias - como blogs, podcasts e tabloides - são altamente comerciais e susceptíveis aos imperativos de mercado, recorrendo a um conteúdo sensacionalista, oferecido constantemente por líderes populistas, para atender a demanda popular imediata (Albertazzi \& Macdonnel, 2008).

Tendo isso em vista, tem-se que não existe uma causa única para a crise na qual se encontra a democracia liberal, mas causas múltiplas e, dentre elas, os impactos da globalização econômica e cultural sobre o contexto de competição política nacional. Assim, a fim de combater o autoritarismo, faz-se imprescindível, além do estabelecimento de políticas que confrontem os efeitos distributivos da globalização, a racionalização do fenômeno a fim de convencer o público democrático, ao invés de estabelecer a globalização como um processo inevitável em direção ao progresso.

A ascensão do populismo é inegável e, para enfrentá-lo, faz-se necessário compreender as preferências de seus apoiadores. Existe uma parcela expressiva do público eleitoral que sente ter sido abandonada e cujas ansiedades e ressentimentos têm sido mobilizados com maestria por líderes autoritários que ocupam cada vez mais espaço dentro dos sistemas democráticos liberais. Nesse sentido, faz-se fundamental, conforme proposto por Chantall Mouffe (2005), o enfrentamento do populismo na esfera política e não na esfera moral. Não se deve suspeitar das tentativas de compreensão do fenômeno populismo, nenhuma delas busca justificar o inaceitável. No entanto, os processos e as instituições democráticas possuem enorme dificuldade em processar antagonismos de ordem moral. É justamente quando a política se 
desenrola no terreno moral, nos lembra Mouffe, que as democracias se encontram mais ameaçadas.

\section{Referências bibliográficas}

ALBERTAZZI, Daniele; MCDONNELL, Duncan. Introduction: The Sceptre and the Spectre. In: ALBERTAZZI, Daniele; MCDONNELL, Duncan (Ed.). Twenty-First Century Populism: The Spectre of Western European Democracy. New York: Palgrave Macmillan, 2008, p. 1-11.

ALESINA, Alberto; MIANO, Armando; STANTCHEVA, Stefanie. Immigration And Redistribution. Nber Working Paper Series, Working Paper 24733. Massachusetts: National Bureau Of Economic Research, jun. 2019. Disponível em: < https://www.nber.org/papers/w24733.pdf > Acessado em: 20 out. 2019.

ALVARES, Claudia; DAHLGREN, Peter. Populism, extremism and media: Mapping na uncertain terrain. European Journal Of Communication, v. 31, n. 1, fev. 2016, p.46-57.

BOBBIO, Norberto. A Liberdade dos Antigos e dos Modernos. In: BOBBIO, Norberto. Liberalismo e Democracia. 6. ed. São Paulo: Editora Brasiliense, 1988.

BOBBIO, Norberto; METTEUCCI, Nicola; PASQUINO, Gianfranco. Dicionário de Política. 11. ed. Brasília: Editora Unb, 1983. 1622 p.

DAHL, Robert A. A Preface to Democratic Theory. 3. ed. London: The University Of Chicago Press, 1956. 171 p.

FELLER, Erika. International Refugee Protection 50 years on: The protection challenges of the past, present and future. International Review Of The Red Cross, v. 83, n. 843, p. 581606, set. 2001. Disponível em:

<https://www.icrc.org/eng/resources/documents/article/other/57jre4.htm>. Acessado em: 03 nov. 2017.

HUNTINGTON, Samuel P. O Choque de Civilizações e a Recomposição da Ordem Mundial. Rio de Janeiro: Objetiva, p. 456. 1996.

IKENBERRY, G. John. The Liberal International Order and its Discontents. Millennium: Journal of International Studies, v. 38, n. 3, mai. 2010, p.509-521.

INGLEHART, Ronald F.; NORRIS, Pippa. Trump, Brexit, and the Rise of Populism: Economic Have-Nots and Cultural Backlash. Faculty Harvard Kennedy School Faculty Research Working Paper Series, Working Paper n. RWP16-026, ago. 2016, p.1-52. Disponível em: <https://www.hks.harvard.edu/publications/trump-brexit-and-rise-populismeconomic-have-nots-and-cultural-backlash> Acessado em: 20 ago. 2019.

KRIESI, Hanspeter et al. West European Politics in the Age of Globalization. New York: Cambridge University Press, 2008. 428 p.

KRUGMAN, Paul. Economics in Crisis. Notas Económicas, v. 22, n. 5, jun. 2013, p.12-17. 
MEAD, Walter Russel. The Jacksonian Revolt: American Populism and the liberal order. Foreign Affairs, [s.i.], v. 2, n. 96, p.1-5, abr. 2017. Disponível em:

$<$ http://link.galegroup.com/apps/doc/A487797167/AONE?u=capes\&sid=AONE\&xid=906f2c a6>. Acessado em: 12 jul. 2018.

MOUFFE, Chantal. The 'End of Politics' and the Challenge of Right-wing Populism. In: PANIZZA, Francisco (Ed.). Populism and the Mirror of Democracy. Londres: Verso, 2005.

MUDDE, Cas. The Populist Zeitgeist. Government And Opposition, v. 39, n. 4, p.542-563, set. 2004, p.542-563.

MÜLLER, Jan-Werner. What Is Populism? Philadelphia: University Of Pennsylvania Press, 2016. 123 p.

NYE, Joseph S. Will the Liberal Order Survive? Foreign Affairs, v. 96, n. 1, fev. 2017, p.1016.

ORGANIZAÇÃO PARA A COOPERAÇÃO E DESENVOLVIMENTO ECONÔMICO. Criação de Emprego e Desenvolvimento Econômico Local 2018: Preparando para o Futuro do Trabalho.?, 018. 12 p. Disponível em:

<http://www.oecd.org/newsroom/criaaodeempregoedesenvolvimentoeconomicolocal2018pre pararparaofuturodotrabalho.htm>. Acessado em: 08 jun. 2019.

PANIZZA, Francisco. Introduction: Populism and the Mirror of Democracy. In: Populism and the Mirror of Democracy. Londres: Verso, 2005.

\section{PEW RESEARCH CENTER. Many Across the Globe Are Dissatisfied With How}

Democracy Is Working, 2019. 60 p. Disponível em:

<https://www.pewresearch.org/global/2019/04/29/why-are-people-dissatisfied-with-howdemocracy-is-working/>. Acessado em: 09 jun. 2019.

RODRIK, Dani. Populism and the Economics of Globalization. Journal Of International Business Policy, 22 fev. 2018, p.12-33.

RODRIK, Dani. The Globalization Paradox: Democracy and the Future of World Economy. Nova York: W.W. Norton, 2010. 368 p.

RYDGREN, Jens. France: The FRONT NATIONAL, Ethnonationalism and Populism. In: ALBERTAZZI, Daniele; MCDONNELL, Duncan. Twenty-First Century Populism: The Spectre of Western European Democracy. New York: Palgrave Macmillan, 2008, p. 166-180.

THIRKELL-WHITE, Ben. Dealing with the banks: populism and the public interest in the global financial crisis. International Affairs, [s.i.], v. ?, n. 85, p.689-711, abr. 2009.

WORLD INEQUALITY LAB. World Inequality Report. 2018. 296p. Disponível em: <https://wir2018.wid.world/>. Acessado em: 02 jul. 2018.

ZAHRA, Tara. Europe's Shifting Borders: Migration Returns to the Continent. Foreign Affairs. 11 fev. 2017. Disponível em: <https://www.foreignaffairs.com/articles/europe/201702-11/europes-shifting-borders>. Acessado em: 11 nov. 2017. 